\title{
Liquid Chromatography - Mass Spectrometry Method for the Simultaneous Determination and Confirmation of Seven Active Components in Chinese Medicine Kumu Injection
}

\author{
Zheng-Quan Lai ${ }^{1,2}$, Hui-Jun Liao ${ }^{1,2}$, Siu-Po Ip $^{2}$, Yu-Yang Yi $^{1}$, Shu-Jiang Shi ${ }^{1}$, Ji- \\ Yan Su ${ }^{1,3}$, Xiao-Ping Lai ${ }^{1,3}$, Zi-Ren Su ${ }^{1 *}$ and Zhi-Xiu Lin ${ }^{2 *}$ \\ ${ }^{1}$ New Drug Research \& Development Center, Guangzhou University of Chinese Medicine, Guangzhou, 510006, ${ }^{2}$ School of \\ Chinese Medicine, The Chinese University of Hong Kong, Shatin, N.T., Hong Kong SAR, ${ }^{3}$ Dongguan Mathematical Engineering \\ and Academy of Chinese Medicine, Guangzhou University of Chinese Medicine, Dongguan, 523808, PR China
}

*For correspondence: Email: suziren@gzucm.edu.cn or linzx@cuhk.edu.hk; Tel: +86 203935 8517, +852 3943 6347; Fax: +862039358390, +852 26037203

\begin{abstract}
Purpose: To develop and validate a simple and selective high performance liquid chromatography photo diode array mass spectrometry (HPLC-PDA-MS/MS) method for simultaneous determination and confirmation of seven major active alkaloids (6-Hydroxy- $\beta$-Carboline-1-carboxylic acid, $\beta$-Carboline-1carboxylic acid, $\beta$-Carboline-1-propanoic acid, 3-Methylcanthin-5, 6-dione, 4-Methoxy-3-methylcanthine5,6-dione, 5-Hydroxy-4-methoxycanthin-6-one, 4,5-Dimethoxycanthin-6-one) in Kumu injections (KMIs) Methods: For the analysis of the preparation, the optimal chromatographic condition was achieved on a Phenomenex Gemini $C_{18}$ column with gradient elution of $25 \mathrm{mM}$ aqueous ammonium acetate $(\mathrm{pH}=4.0$ adjusted by glacial acetate acid) and acetonitrile with flow rate at $1.0 \mathrm{~mL} / \mathrm{min}$, column temperature at 35 ${ }^{\circ} \mathrm{C}$ and detection wavelengths at 245, 260 and $271 \mathrm{~nm}$.

Results: Excellent linear behavior over the investigated concentration ranges was observed with regression coeffcient $\left(R^{2}\right)>0.9997$ for all analytes. Intra- and inter-day precisions for all studied constituents ranged from 0.20 to $1.80 \%$. Recoveries of the assayed constituents were in the range of 98.73 to $100.34 \%$. The results showed the contents of these seven marker compounds differed significantly among different batches of KMls both from the same and different manufacturers.

Conclusion: The validated method was reliable, accurate, repeatable and can be applied to routine quality assessment of these active components in KMIs.
\end{abstract}

Keywords: Alkaloids, High performance liquid chromatography, Photo diode array, Mass spectrometry, Kumu injection, Quality control

Tropical Journal of Pharmaceutical Research is indexed by Science Citation Index (SciSearch), Scopus, International Pharmaceutical Abstract, Chemical Abstracts, Embase, Index Copernicus, EBSCO, African Index Medicus, JournalSeek, Journal Citation Reports/Science Edition, Directory of Open Access Journals (DOAJ), African Journal Online, Bioline International, Open-J-Gate and Pharmacy Abstracts

\section{INTRODUCTION}

It was about seventy years ago that injections were introduced into traditional Chinese medicine (TCM) domain as a new and important dosage form, which has since substantially changed the impression of TCM from being perceived as slow and weak acting into one with rapid onset and higher efficacy [1]. TCM injections have played an indispensable role in emergency medicine today owing to its ability to bypass the first pass metabolism and the active ingredients can be directly distributed into blood circulation to exert rapid therapeutic effect. However, the use of 
TCM injections is often associated with adverse drug reactions (ADR). The ADR of TCM injections can manifest as drug fever, disorders of skin and appendages, circulatory system allergy reaction, and even anaphylactic shock in severe case. TCM injection-associated ADR could occur when changing the injection products to that of different manufacturers or to different batches of the same manufacturer. This observation underscores the generally undesirable quality of TCM injection products in the market and the huge challenge facing quality control of injection form of Chinese medicine [2]. Kumu injection (KMI), a widely used Chinese herbal preparation in China and officially recorded in the Drug Standard of Ministry of Public Health of the People's Republic of China, is made from a single Chinese herbal Picrasma quassioides (kumu in Chinese). Kumu has the functions of heat-clearing, detoxification, and anti-inflammation in Chinese medicine practice. Because of the above therapeutic functions, KMI is extensively used for the treatment of cold, upper respiratory tract inflection, acute tonsillitis, enteritis, and bacillary dysentery [3]. Pharmacological and phytochemical studies on $P$. quassioides and $\mathrm{KMI}$ have shown that alkaloids are the main active ingredients responsible for the overall therapeutic effects of KMI. The $P$. quassioides-derived alkaloids, which can be broadly divided into $\beta$-carboline and canthinones types, have shown potent activities against infection and abscess of respiratory, digestive and urinary systems [4-8]. Among these alkaloids, 4,5-dimethoxycanthin-6-one possesses therapeutic action against ulcerative colitis [9], 5-hydroxy-4-methoxycanthin-6-one exhibits inhibitory effect against tobacco mosaic virus [6], while 3-methylcanthin-5,6-dione shows significant anti-inflammatory and antioxidant activities [10]. Due to the biological activities of these alkaloids, their quantitative measurement in Kumu product is of great importance for its quality control.

Several qualitative and quantitative analytical methods such as thin layer chromatography [11], gravimetry [3] and HPLC [12] have been developed for quality assessment of $\mathrm{KMI}$. However, all these methods suffered from either low resolution, low sensitivity or identification of few marker constituents (less than three analytes) and are inadequate for revealing the synergistic effects and complex constituents of KMI. Therefore, an analytical method with capability for multi-targets determination is urgently needed to establish the quality control and enhance the clinical safety and efficacy of KMI.
We report for the first time in this paper a new, simple, sensitive and reliable HPLC-PDA-MS/MS method for simultaneous identification and determination of seven major alkaloids i.e. 6hydroxy- $\beta$-carboline-1-carboxylic acid (a), $\beta$ carboline-1-carboxylic acid (b), $\beta$-carboline-1propanoic acid (c), 3-methylcanthin-5,6-dione (d), 4-methoxy-3-methylcanthine-5,6-dione (e), 5-hydroxy-4-methoxycanthin-6-one (f), 4,5dimethoxycanthin-6-one (g) in 20 commercial products of KMI.

\section{EXPERIMENTAL}

\section{Chemicals and materials}

Acetonitrile, methanol, ammonium acetate and glacial acetate acid were of HPLC-grade (Merck, Darmstadt, Germany). LC-MS grade water was purchased from Fisher Scientific (Massachusetts, USA). Redistilled water was used for the preparation of two-phase mobile solvent system. All other reagents used in this study were of analytical grade from Guanghua Chemicals Co., Ltd (Guangzhou, Guangdong Province, China).

Seven reference standards, i.e. 6-hydroxy- $\beta$ carboline-1-carboxylic acid (a), $\beta$-carboline-1carboxylic acid (b), $\beta$-carboline-1-propanoic acid (c), 3-methylcanthin-5,6-dione (d), 4-methoxy-3methylcanthine-5,6-dione (e), 5-hydroxy-4methoxycanthin-6-one (f), 4,5-dimethoxycanthin6 -one $(\mathbf{g})$ were isolated in our laboratory from the stems of $P$. quassioides and their identities were verified by ESI-MS and ${ }^{1} \mathrm{H}$ and ${ }^{13} \mathrm{C}$-NMR spectrometric techniques and comparing with literature data $[13,14]$. The purity of each compound is higher than $98 \%$ based on HPLCPDA purity test. The chemical structures of the above-mentioned alkaloids are shown in Figure 1.

Negative control preparation (NC) and a total of 20 batches of KMls were provided by Qingfeng Pharmaceutical Company (Ganzhou, Jiangxi Province, China) and Wannianqing Pharmaceutical Company (Shantou, Guangdong Province, China).

\section{HPLC system and conditions}

Shimadzu LC-20A HPLC system (Shimadzu, Kyoto, Japan) comprising of a SPD-M20A PDA detector, a LC-20AT pump, a SIL-20AC automatic sampler, and a CTO-20A thermostatic column compartment was applied for chromatographic analysis. The separation was performed on Gemini $\mathrm{C}_{18}$ column $(4.6 \times 250 \mathrm{~mm}$, $5 \mu \mathrm{m}$, Phenomenex Inc., CA, USA) protected by a Security Guard $\mathrm{C}_{18}$ guard column $(4.0 \times 3.0$ 


\begin{tabular}{|c|c|c|c|c|c|c|}
\hline & I & II & & & III & \\
\hline $\begin{array}{l}\text { Comp- } \\
\text { ounds }\end{array}$ & Chemical name & Nucleus & $\mathrm{R}_{1}$ & $\mathrm{R}_{2}$ & $\begin{array}{l}t_{R} \\
(\min )\end{array}$ & MS data \\
\hline a & $\begin{array}{l}\text { 6-Hydroxy- } \beta \text {-Carboline- } \\
\text { 1-carboxylic acid }\end{array}$ & I & $\mathrm{COOH}$ & $\mathrm{OH}$ & 7.10 & $\begin{array}{l}229.1[\mathrm{M}+\mathrm{H}]^{+}, 251.0[\mathrm{M}+\mathrm{Na}]^{+}, 211.0 \\
{\left[\mathrm{M}+\mathrm{H}-\mathrm{H}_{2} \mathrm{O}\right]^{+}}\end{array}$ \\
\hline b & $\begin{array}{l}\beta \text {-carboline-1- } \\
\text { carboxylic acid }\end{array}$ & I & $\mathrm{COOH}$ & $\mathrm{H}$ & 20.86 & $\begin{array}{l}213.1[\mathrm{M}+\mathrm{H}]^{+}, 235.0[\mathrm{M}+\mathrm{Na}]^{+}, 195.1 \\
{\left[\mathrm{M}+\mathrm{H}-\mathrm{H}_{2} \mathrm{O}\right]^{+}}\end{array}$ \\
\hline c & $\begin{array}{l}\beta \text {-carboline-1- } \\
\text { propanoic acid }\end{array}$ & I & $\begin{array}{l}\mathrm{CH}_{2} \mathrm{CH}_{2} \\
\mathrm{COOH}\end{array}$ & $\mathrm{H}$ & 22.78 & $\begin{array}{l}241.2[\mathrm{M}+\mathrm{H}]^{+}, 263.1[\mathrm{M}+\mathrm{Na}]^{+}, 223.1 \\
{\left[\mathrm{M}+\mathrm{H}-\mathrm{H}_{2} \mathrm{O}\right]^{+}}\end{array}$ \\
\hline d & $\begin{array}{l}\text { 3-methylcanthin-5,6- } \\
\text { dione }\end{array}$ & II & - & - & 33.85 & $\begin{array}{l}251.2[\mathrm{M}+\mathrm{H}]^{+}, 273.1[\mathrm{M}+\mathrm{Na}]^{+}, 236.0 \\
{\left[\mathrm{M}+\mathrm{H}-\mathrm{CH}_{3}\right]^{+}}\end{array}$ \\
\hline e & $\begin{array}{l}\text { 4-methoxy-3- } \\
\text { methylcanthine-5,6- } \\
\text { dione }\end{array}$ & II & $\mathrm{OCH}_{3}$ & - & 35.22 & $\begin{array}{l}281.2[\mathrm{M}+\mathrm{H}]^{+}, 303.0[\mathrm{M}+\mathrm{Na}]^{+}, 266.1 \\
{\left[\mathrm{M}+\mathrm{H}-\mathrm{CH}_{3}\right]^{+}}\end{array}$ \\
\hline$f$ & $\begin{array}{l}\text { 5-hydroxy-4- } \\
\text { methoxycanthin-6-one }\end{array}$ & III & $\mathrm{OCH}_{3}$ & $\mathrm{OH}$ & 50.88 & $\begin{array}{l}267.2[\mathrm{M}+\mathrm{H}]^{+}, 289.0[\mathrm{M}+\mathrm{Na}]^{+}, 252.0 \\
{\left[\mathrm{M}+\mathrm{H}-\mathrm{CH}_{3}\right]^{+}}\end{array}$ \\
\hline g & $\begin{array}{l}\text { 4,5-dimethoxycanthin- } \\
6 \text {-one }\end{array}$ & III & $\mathrm{OCH}_{3}$ & $\mathrm{OCH}_{3}$ & 55.51 & $\begin{array}{l}281.2[\mathrm{M}+\mathrm{H}]^{+}, 303.0[\mathrm{M}+\mathrm{Na}]^{+}, 266.0 \\
{\left[\mathrm{M}+\mathrm{H}-\mathrm{CH}_{3}\right]^{+}}\end{array}$ \\
\hline
\end{tabular}

Figure 1: Chemical structures and MS data of the seven alkaloids

$\mathrm{mm}, 5 \mu \mathrm{m}$, Phenomenex Inc., CA, USA) with a flow rate of $1.0 \mathrm{~mL} / \mathrm{min}$, temperature at $35{ }^{\circ} \mathrm{C}$ and injection volume of $10 \mu \mathrm{L}$. The mobile phase consisting of solvent $\mathrm{A}(25 \mathrm{mM}$ aqueous ammonium acetate adjusted with glacial acetic acid to $\mathrm{pH} \mathrm{4.0)}$ and solvent $\mathrm{B}$ (acetonitrile) was used to elute the targets with the gradient mode (0-30 min: $12 \%$ B $\rightarrow 15 \%$ B; $30-50$ min: $15 \%$ B $\rightarrow 45 \%$ B; $50-55$ min: $45 \%$ B $\rightarrow 12 \%$ B; $55-60$ min: $12 \%$ B). The absorption spectra of the compounds were recorded from 190 to $400 \mathrm{~nm}$. The detection wavelengths were set at $245 \mathrm{~nm}$ for compounds c, $\mathbf{d}$ e, $\mathbf{f}$ and $\mathbf{g}, 260 \mathrm{~nm}$ for compound $\mathbf{b}$, and $271 \mathrm{~nm}$ for compound $\mathbf{a}$.

\section{LC-MS system and conditions}

Agilent G6410 Triple Quad LC/MS (Agilent Technologies, MA, USA) was used for mass spectrometric measurements. The same separation conditions as described in HPLC-PDA analysis were used. By solvent splitting, 0.5 $\mathrm{mL} / \mathrm{min}$ portion of the column effluent was delivered into the ion source of the mass spectrometer. Data acquisition was performed on a MassHunter software system. The conditions of MS analysis were as follows: dry gas $\left(\mathrm{N}_{2}\right)$ flow rate, $10 \mathrm{~L} / \mathrm{min}$; dry gas temperature, $325{ }^{\circ} \mathrm{C}$; nebulizer pressure, $35 \mathrm{psi}$; source voltage, 4000 $\mathrm{V}$. The mass spectrometric data was acquired from $\mathrm{m} / \mathrm{z} 100$ to 1000 in positive ion mode.

\section{Preparation of standard solutions and sample solutions}

A mixed standard stock solution containing the seven analytes was prepared by dissolving each standard in methanol to obtain the concentrations of $30 \mu \mathrm{g} / \mathrm{mL}$ for 6-hydroxy- $\beta$ carboline-1-carboxylic acid (a), $153 \mu \mathrm{g} / \mathrm{mL}$ for $\beta$ carboline-1-carboxylic acid (b), $22.8 \mu \mathrm{g} / \mathrm{mL}$ for $\beta$ carboline-1-propanoic acid (c), $11.4 \mu \mathrm{g} / \mathrm{mL}$ for 3 methylcanthin-5,6-dione (d), $7.2 \mu \mathrm{g} / \mathrm{mL}$ for 4 methoxy-3-methylcanthine-5,6-dione (e), 12 $\mu \mathrm{g} / \mathrm{mL}$ for 5-hydroxy-4-methoxycanthin-6-one (f) and $3 \mu \mathrm{g} / \mathrm{mL}$ for 4,5 -dimethoxycanthin-6-one $(\mathbf{g})$. Then the stock was diluted with methanol to 1 , $2 / 3,1 / 2,1 / 3,1 / 6,1 / 10$ and $1 / 30$ of the original stock solution to serve as working solutions for establishing calibration curves. All of the standard solutions were stored at $4{ }^{\circ} \mathrm{C}$ and brought to room temperature before use. 
Sample solution was prepared by filtration of an aliquot of the KMI through a $0.45 \mu \mathrm{m}$ membrane before it was injected into HPLC analysis.

\section{Statistical analysis}

All data analyses were carried out using GraphPad Prism 5 statistical software. The datasets were analyzed using the unpaired t-test. A $p$-value of $<0.05$ was considered statistically significant.

\section{RESULTS}

\section{Optimization of chromatographic conditions}

In order to obtain chromatograms with a good resolution of the targeted analyte peaks, various chromatographic parameters were optimized. Five different analytical columns, i.e., Phenomenex Luna $\mathrm{C}_{18}$, Phenomenex Gemini $\mathrm{C}_{18}$, YMC Pack ODS, Agilent Zorbax SB- $\mathrm{C}_{18}$ and Waters Symmetry Shield $\mathrm{RP}_{18}$ were initially screened and the best resolution was achieved with Gemini $\mathrm{C}_{18}$ from Phenomenex. Suitable mobile phase compositions (acetonitrile-aqueous ammonium acetate, acetonitrile-phosphoric buffer, acetonitrile-aqueous sodium dodecyl benzene sulfonate, acetonitrile-ammonia) were also investigated and the acetonitrile-aqueous ammonium acetate system showed more powerful separation ability than other systems. The retention behavior of the compounds on the reversed-phase HPLC column was significantly affected by the $\mathrm{pH}$ of the mobile phase, thus different mobile phase $\mathrm{pH}(\mathrm{pH} 3.5,4.0,4.5$ and 5.0 ) adjusted by glacial acid were compared and the peak tailing eliminated at $\mathrm{pH} 4.0$. Besides, column temperatures $\left(25,30\right.$ and $\left.35^{\circ} \mathrm{C}\right)$ were also optimized. As a result, better peak shape was achieved at temperature of $35{ }^{\circ} \mathrm{C}$. Furthermore, according to maximum absorption of the standards, the optimal wavelengths were determined to be $245 \mathrm{~nm}$ for compound $\mathbf{c}, \mathbf{d} \mathbf{e}, \mathbf{f}$ and $\mathbf{g}, 260 \mathrm{~nm}$ for compound $\mathbf{b}$ and $271 \mathrm{~nm}$ for compound a, respectively. Typical HPLC-PDA chromatograms of reference compounds, KMI samples and negative control preparation are shown in Figure 2.

\section{LC-MS identity confirmation}

HPLC-PDA-MS/MS was employed to identify the seven alkaloids (compounds a-g) from KMl. By comparison with retention times, UV spectra data, precursor ions, and diagnostic fragment ions of the authentic compounds, seven alkaloids in HPLC chromatogram of KMl were unambiguously identified as 6-hydroxy- $\beta$ carboline-1-carboxylic acid (peak a), $\beta$-carboline- 1-carboxylic acid (peak b), $\beta$-carboline-1propanoic acid (peak c), 3-methylcanthin-5,6dione (peak d), 4-methoxy-3-methylcanthine-5,6dione (peak e), 5-hydroxy-4-methoxycanthin-6one (peak f) and 4,5-dimethoxycanthin-6-one (peak g), respectively (Figure 2). As listed in Figure 1, quasi-molecular ions $(\mathrm{M}+\mathrm{H})^{+}$and $(\mathrm{M}+\mathrm{Na})^{+}$were observed for all the investigated compounds. Their fragmentation patterns matched well with their chemical structures. The successful identification of the seven compounds is of importance in establishing an accurate and feasible method for the quality control of this preparation.

\section{Calibration curves, LODs and LOQs}

The calibration curves were performed with working solutions at 7 different concentrations mentioned above in triplicate. The regression equations were calculated using the formula $y=$ $a x+b$, where $y$ and $x$ were peak area and concentration $(\mu \mathrm{g} / \mathrm{mL})$, respectively. The working solutions were further diluted to a series of concentrations with methanol to calculate the limits of detection (LODs) and limits of quantification (LOQs) when signal-to-noise ratio $(\mathrm{S} / \mathrm{N})$ amounted to 3 and 10 , respectively. Good linearity $\left(R^{2}>0.9997\right)$ was achieved within the investigated ranges for all the analytes. The LODs of seven alkaloids ranged from 0.022 to $0.345 \mu \mathrm{g} / \mathrm{mL}$ and LOQs were within 0.073-1.153 $\mu \mathrm{g} / \mathrm{mL}$ (Table 1).

\section{Precision, repeatability, stability and accuracy}

Intra-day and inter-day variations were chosen to measure the precision of the developed method by analyzing $1,1 / 3,1 / 10$ dilutions of the mixed standard solution. The intra-day and inter-day precisions were determined by assaying standard solutions at the three concentrations in six replicates within a single day and once a day for three sequential days, respectively. The RSDs of intra-day and inter-day precisions for all the components under investigation were less than $2 \%$ (Table 2).

Repeatability was investigated by analyzing six independently prepared solutions (No. 20110321) and each of them was injected into the apparatus at $0,4,8,12,24$ and $48 \mathrm{~h}$, respectively, to determine the stability of the solution. The RSDs of repeatability and stability of the seven compounds were all less than $3 \%$ (Table 2).

Accuracy was determined by recovery test. The known quantities of the marker compounds were 

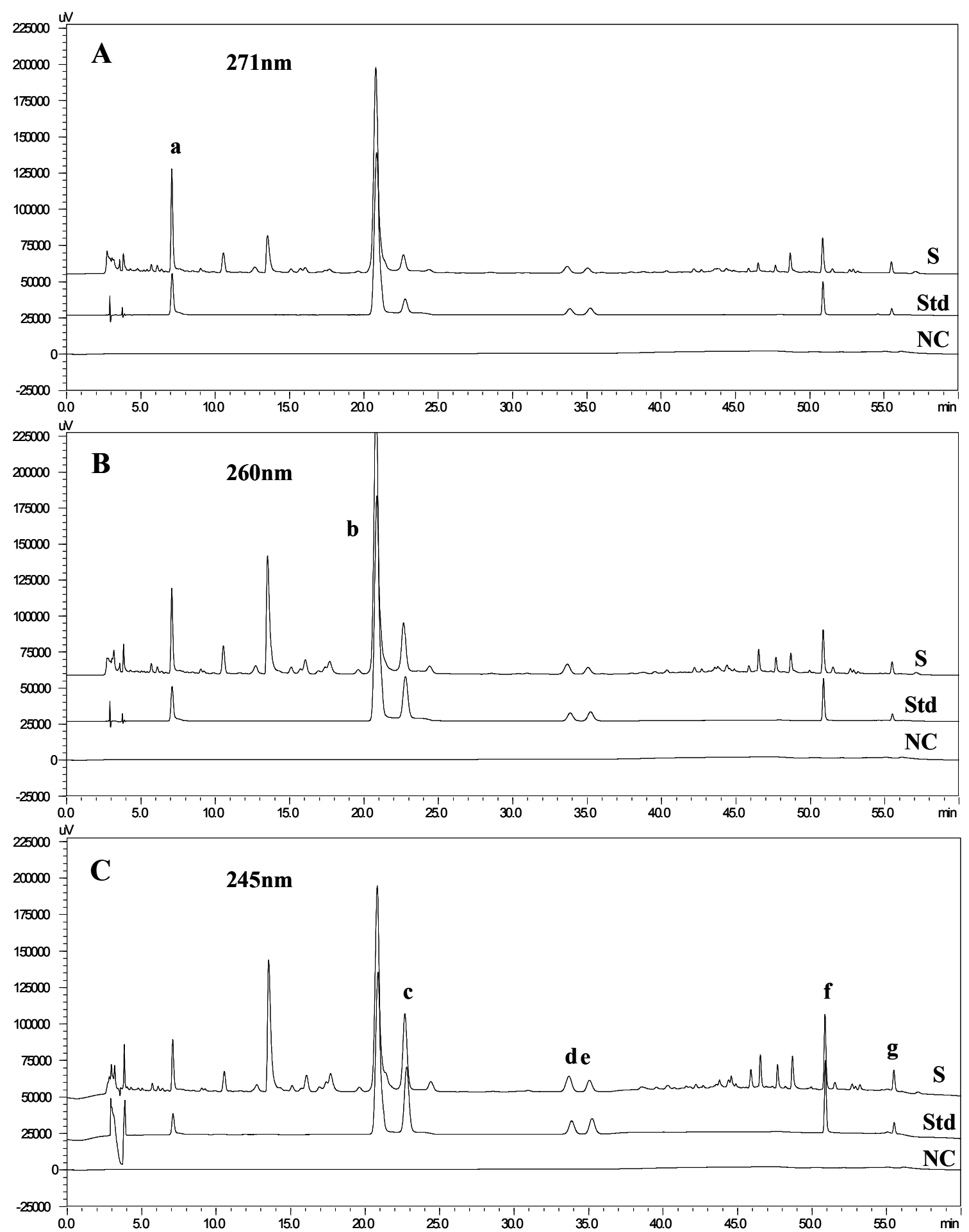

Figure 2: Comparative chromatograms of representative KMI samples (S, 20110321), mixed standard solution (Std) and negative control preparation (NC) in different wavelengths: (A) $271 \mathrm{~nm}$; a represent 6-Hydroxy- $\beta$ Carboline-1-carboxylic acid; (B) $260 \mathrm{~nm}$; b represent $\beta$-Carboline-1-carboxylic acid; (C) $245 \mathrm{~nm}$; c, d, e, f, g represent $\beta$-Carboline-1-propanoic acid, 3-Methylcanthin-5,6-dione 4-Methoxy-3-methylcanthine-5,6-dione, 5Hydroxy-4-methoxycanthin-6-one and 4,5-Dimethoxycanthin-6-one respectively.

spiked to the known aliquots of the sample solution (No. 20110321) that had previously been analyzed. Recovery was between $98.73 \%$ and $100.34 \%$ with RSDs less than $3 \%$ for all the seven marker compounds (Table 2).
The validation results strongly indicated that the HPLC-PDA method was reproducible and suitable for simultaneous quantitation of seven alkaloids in KMI. 
Table 1: Results of regression analysis on calibration curves

\begin{tabular}{cccccc}
\hline Analyte & Regression equation & $R^{2}$ & $\begin{array}{c}\text { Linear range } \\
(\mu \mathrm{g} / \mathrm{mL})\end{array}$ & $\begin{array}{c}\mathrm{LOD} \\
(\mu \mathrm{g} / \mathrm{mL})\end{array}$ & $\begin{array}{c}\mathrm{LOQ} \\
(\mu \mathrm{g} / \mathrm{mL})\end{array}$ \\
\hline A & $y=25573.00 x-121.38$ & 0.9997 & $1.00 \sim 30.00$ & 0.223 & 0.751 \\
B & $y=50207.91 x-188245.94$ & 0.9999 & $5.10 \sim 153.00$ & 0.345 & 1.153 \\
C & $y=87367.65 x+12118.45$ & 0.9999 & $0.76 \sim 22.80$ & 0.065 & 0.220 \\
D & $y=57092.13 x-1267.49$ & 0.9997 & $0.38 \sim 11.40$ & 0.041 & 0.140 \\
E & $y=81613.66 x-4695.97$ & 1.0000 & $0.24 \sim 7.20$ & 0.039 & 0.132 \\
F & $y=49848.43 x-4880.84$ & 0.9999 & $0.40 \sim 12.00$ & 0.047 & 0.154 \\
G & $y=31433.97 x+771.15$ & 0.9998 & $0.10 \sim 3.00$ & 0.022 & 0.073 \\
\hline
\end{tabular}

Table 2: Results of precision, repeatability, stability and recovery analyses on the seven alkaloids found in KMI

\begin{tabular}{|c|c|c|c|c|c|c|c|}
\hline \multirow[b]{2}{*}{ Analyte } & \multicolumn{3}{|c|}{ Precision } & \multirow{2}{*}{$\begin{array}{c}\text { Repeatability } \\
\text { RSD }(\%) \\
(n=6)\end{array}$} & \multirow{2}{*}{$\begin{array}{c}\text { Stability } \\
\text { RSD }(\%) \\
(n=6)\end{array}$} & \multicolumn{2}{|c|}{ Recovery } \\
\hline & $\begin{array}{c}\text { Concentration } \\
(\mu \mathrm{g} / \mathrm{mL})\end{array}$ & $\begin{array}{c}\text { Intra-day } \\
\text { RSD }(\%)(n=6)\end{array}$ & $\begin{array}{c}\text { Inter-day } \\
\text { RSD }(\%)(n=3)\end{array}$ & & & $\begin{array}{c}(\%) \\
(n=6)\end{array}$ & $\begin{array}{l}\text { RSD } \\
(\%)\end{array}$ \\
\hline \multirow{4}{*}{ a } & 3.00 & 1.03 & 0.87 & & & & \\
\hline & 10.00 & 1.05 & 0.64 & 0.76 & 0.94 & 99.95 & 1.87 \\
\hline & 30.00 & 0.68 & 0.54 & & & & \\
\hline & 15.30 & 0.92 & 0.67 & & & & \\
\hline \multirow[t]{3}{*}{ b } & 51.00 & 1.80 & 1.48 & 0.60 & 1.35 & 99.73 & 2.14 \\
\hline & 153.00 & 1.04 & 0.70 & & & & \\
\hline & 2.28 & 1.30 & 1.59 & & & & \\
\hline \multirow[t]{3}{*}{ c } & 7.60 & 1.74 & 1.11 & 2.20 & 1.56 & 98.73 & 1.98 \\
\hline & 22.80 & 1.35 & 1.15 & & & & \\
\hline & 1.14 & 0.64 & 0.52 & & & & \\
\hline \multirow[t]{3}{*}{ d } & 3.80 & 0.49 & 0.39 & 0.40 & 0.48 & 100.33 & 1.23 \\
\hline & 11.40 & 0.55 & 0.47 & & & & \\
\hline & 0.72 & 0.46 & 0.51 & & & & \\
\hline \multirow[t]{3}{*}{ e } & 2.40 & 0.88 & 0.77 & 0.82 & 0.85 & 100.34 & 1.65 \\
\hline & 7.20 & 0.54 & 0.56 & & & & \\
\hline & 1.20 & 0.20 & 0.36 & & & & \\
\hline \multirow[t]{3}{*}{ f } & 4.00 & 0.81 & 0.67 & 0.37 & 0.62 & 99.59 & 1.38 \\
\hline & 12.00 & 0.77 & 0.70 & & & & \\
\hline & 0.30 & 0.66 & 0.64 & & & & \\
\hline \multirow[t]{2}{*}{ g } & 1.00 & 0.34 & 0.98 & 0.34 & 0.58 & 99.97 & 0.85 \\
\hline & 3.00 & 0.46 & 0.40 & & & & \\
\hline
\end{tabular}

\section{Sample analysis}

The proposed method was subsequently applied to simultaneously determine the seven alkaloids in 20 batches of commercially-available KMI from two manufacturers, and the contents of the investigated constituents are tabulated in Table 3 , in which 6-hydroxy- $\beta$-carboline-1-carboxylic acid (a), $\beta$-carboline-1-carboxylic acid (b) and $\beta$ carboline-1-propanoic acid (c) were observed to be more abundant than the rest four marker constituents among all the 20 batches of KMI samples. However, there were large differences between the samples of the two origins, which not only manifested in that $\beta$-carboline-1carboxylic acid (b) was highest in content, accounting for about $60 \%$ of the total seven alkaloids among the samples from Qingfeng while $\beta$-carboline-1-propanoic acid (c) was the most abundant accounting for approximately $40 \%$ of the seven analytes in samples from Wannianqing. Also the total contents of the seven target compounds showed significant variations between samples from the different manufacturers according to statistical results. Furthermore, the average contents of compounds a-e were much higher among samples from Qingfeng than those from Wannianqing with only exception of $\beta$-carboline1-propanoic acid (c). Also, large quality fluctuations obviously existed among the samples from the same manufacturer.

\section{DISCUSSION}

Based on the results of these analyses of the contents of the seven bioactive compounds of $\mathrm{KMI}$, large quality variations among all these products obviously existed among the samples both from the same and different manufacturers, which may arise from the different sources of the raw herbal materials, material collection if plant were at different times of the year, disparity in preparation technology in different factories, and lack of effective quality control method to maintain the quality consistency of the preparation. All these factors 
Table 3: Contents $(\mu \mathrm{g} / \mathrm{mL})$ of the seven alkaloids in $\mathrm{KMl}$

\begin{tabular}{|c|c|c|c|c|c|c|c|c|c|c|}
\hline \multirow{2}{*}{ No. } & \multirow{2}{*}{ Batch No. } & \multirow{2}{*}{ source } & \multicolumn{8}{|c|}{ Content of Analytes (mean $\pm S D, \mu g / m L n=3$ ) } \\
\hline & & & a & $\mathbf{b}$ & c & D & $\mathbf{E}$ & $f$ & $\mathbf{g}$ & Total \\
\hline 1 & 20110321 & Qingfeng & $27.61 \pm 0.03$ & $94.55 \pm 0.24$ & $13.27 \pm 0.24$ & $5.15 \pm 0.02$ & $2.51 \pm 0.01$ & $6.96 \pm 0.05$ & $2.80 \pm 0.02$ & 152.85 \\
\hline 2 & 20110429 & Qingfeng & $18.52 \pm 0.12$ & $75.18 \pm 0.08$ & $10.79 \pm 0.04$ & $4.01 \pm 0.01$ & $1.98 \pm 0.02$ & $4.40 \pm 0.08$ & $1.59 \pm 0.03$ & 116.47 \\
\hline 3 & 20110616 & Qingfeng & $19.34 \pm 0.01$ & $64.61 \pm 0.04$ & $11.08 \pm 0.01$ & $3.64 \pm 0.05$ & $1.72 \pm 0.06$ & $4.35 \pm 0.06$ & $2.02 \pm 0.02$ & 106.76 \\
\hline 4 & 20110729 & Qingfeng & $27.97 \pm 0.09$ & $93.84 \pm 0.10$ & $17.14 \pm 0.04$ & $4.57 \pm 0.02$ & $2.66 \pm 0.01$ & $7.13 \pm 0.04$ & $3.09 \pm 0.01^{<}$ & 156.40 \\
\hline 5 & 20110823 & Qingfeng & $6.64 \pm 0.02$ & $27.33 \pm 0.01$ & $4.39 \pm 0.01$ & $1.12 \pm 0.01$ & $0.41 \pm 0.01$ & $0.29 \pm 0.01^{<}$ & $0.26 \pm 0.00$ & 40.44 \\
\hline 6 & 20110919 & Qingfeng & $19.75 \pm 0.01$ & $49.68 \pm 0.11$ & $9.03 \pm 0.01$ & $2.70 \pm 0.03$ & $1.19 \pm 0.01$ & $2.34 \pm 0.02$ & $1.19 \pm 0.00$ & 85.88 \\
\hline 7 & 20111008 & Qingfeng & $12.10 \pm 0.01$ & $35.01 \pm 0.11$ & $6.56 \pm 0.01$ & $1.76 \pm 0.01$ & $0.71 \pm 0.02$ & $0.63 \pm 0.03$ & $0.50 \pm 0.01$ & 57.27 \\
\hline 8 & 20111127 & Qingfeng & $11.97 \pm 0.08$ & $36.08 \pm 0.28$ & $4.81 \pm 0.03$ & $1.12 \pm 0.01$ & $0.46 \pm 0.01$ & $0.46 \pm 0.02$ & $0.47 \pm 0.02$ & 55.37 \\
\hline 9 & 20120105 & Qingfeng & $11.83 \pm 0.01$ & $36.13 \pm 0.08$ & $6.78 \pm 0.04$ & $1.73 \pm 0.02$ & $0.66 \pm 0.01$ & $0.29 \pm 0.00^{<}$ & $0.42 \pm 0.00$ & 57.83 \\
\hline 10 & 20120107 & Qingfeng & $7.72 \pm 0.03$ & $24.97 \pm 0.14$ & $4.85 \pm 0.01$ & $0.92 \pm 0.01$ & $0.45 \pm 0.01$ & $0.38 \pm 0.00$ & $0.51 \pm 0.01$ & 39.80 \\
\hline 11 & 20110317 & Wannianqing & $10.12 \pm 0.05$ & $16.90 \pm 0.01$ & $24.19 \pm 0.07^{<}$ & $1.70 \pm 0.00$ & - & $2.41 \pm 0.07$ & $0.96 \pm 0.00$ & 56.28 \\
\hline 12 & 20110320 & Wannianqing & $14.79 \pm 0.03$ & $48.18 \pm 0.42$ & $41.49 \pm 0.04^{<}$ & $2.24 \pm 0.06$ & $0.34 \pm 0.01$ & $3.35 \pm 0.08$ & $3.26 \pm 0.03^{<}$ & 113.65 \\
\hline 13 & 20110418 & Wannianqing & $5.97 \pm 0.09$ & $4.70 \pm 0.00^{<}$ & $17.01 \pm 0.03$ & $0.50 \pm 0.00$ & $0.25 \pm 0.01$ & $0.93 \pm 0.00$ & $0.38 \pm 0.01$ & 29.74 \\
\hline 14 & 20110420 & Wannianqing & $4.92 \pm 0.02$ & $4.30 \pm 0.01^{<}$ & $7.45 \pm 0.02$ & $0.25 \pm 0.00^{<}$ & $0.18 \pm 0.00$ & $0.59 \pm 0.01$ & $0.11 \pm 0.00^{<}$ & 17.80 \\
\hline 15 & 20110501 & Wannianqing & $6.21 \pm 0.07$ & $4.58 \pm 0.01^{<}$ & $13.98 \pm 0.37$ & $0.40 \pm 0.01$ & $0.22 \pm 0.00^{<}$ & $0.94 \pm 0.02$ & $0.28 \pm 0.00$ & 26.61 \\
\hline 16 & 20110523 & Wannianqing & $6.50 \pm 0.03$ & $6.05 \pm 0.03$ & $14.68 \pm 0.04$ & $0.22 \pm 0.00^{<}$ & $0.25 \pm 0.01$ & $1.58 \pm 0.03$ & $0.16 \pm 0.00$ & 29.44 \\
\hline 17 & 20110606 & Wannianqing & $9.25 \pm 0.06$ & $14.20 \pm 0.01$ & $29.81 \pm 0.05^{<}$ & $0.98 \pm 0.00$ & $0.62 \pm 0.01$ & $3.34 \pm 0.04$ & $0.70 \pm 0.01$ & 58.90 \\
\hline 18 & 20110616 & Wannianqing & $8.82 \pm 0.11$ & $12.24 \pm 0.01$ & $25.34 \pm 0.01^{<}$ & $0.57 \pm 0.01$ & $0.56 \pm 0.01$ & $1.63 \pm 0.00$ & $0.36 \pm 0.00$ & 49.52 \\
\hline 19 & 20110708 & Wannianqing & $8.76 \pm 0.09$ & $8.12 \pm 0.00$ & $18.01 \pm 0.06$ & $0.60 \pm 0.01$ & $0.17 \pm 0.00^{<}$ & $1.59 \pm 0.04$ & $0.18 \pm 0.00$ & 37.43 \\
\hline 20 & 20110713 & Wannianqing & $6.53 \pm 0.01$ & $5.91 \pm 0.01$ & $13.66 \pm 0.02$ & $0.36 \pm 0.00^{<}$ & - & $1.02 \pm 0.02$ & - & 27.47 \\
\hline
\end{tabular}

(-) Lower than test limit and could not be quantified; ${ }^{2}$ Out of linear range. 
would definitely affect their therapeutic efficacies and even safety. It is also worth noting that compound $d$, e, $f, g$ believed as important bioactive compounds $[6,9,10]$, were prone to huge loss during the preparation due to their small polar and weak water-soluble properties. There is certainly room for proper care in plant collection, processing and technical improvement in the preparation of the KMI to reduce the loss of these constituents.

\section{CONCLUSION}

Efficient and reliable analytical protocols to evaluate and control the quality of TCM injections are urgently needed to minimize the ADR associated with the use of this dosage form of Chinese herbal products. We have successfully developed a powerful and reliable analytical method for quality evaluation of KMI through identification and simultaneous quantitation of seven major alkaloids of KMI, namely 6-hydroxy$\beta$-carboline-1-carboxylic acid, $\beta$-Carboline-1carboxylic acid, $\beta$-carboline-1-propanoic acid, 3methylcanthin-5,6-dione, 4-methoxy-3-methylcanthine-5,6-dione, 5-hydroxy-4-methoxycanthin-6-one, 4,5-dimethoxycanthin-6-one by HPLC-PDA-MS-MS. This method has been proven to be sensitive, accurate and reproducible and could provide valuable quantitative information for the quality assessment of KMI.

\section{ACKNOWLEDGEMENT}

Zheng-Quan Lai and Hui-Jun Liao contributed equally to this work. The authors are grateful for the financial support of the State Natural Science Funds Commission of the People's Republic of China (Project no. u0732004), the Science and Technology Planning Project of Guangdong Province (no. 2009A030100014) and Guangdong Province Universities and Colleges Pearl River Scholar Funded Scheme (2011).

\section{REFERENCES}

1. Liang AH, Li LD. The Status and Problems of Traditional Chinese Medicinal Injection. Chin. J. of Chin. Mater. Med 2007; 32(11): 1118-1120.

2. Zhou CF, Xu ZL, Lin YH. Review and prospect of traditional Chinese medicinal injection. Chin J of Chin Mater Med 2006; 31(11): 2094-2096.

3. Pharmacopoeia Commission of PRC. Drug Standard of Ministry of Public Health of the People's Republic of China (WS3-B-3887-98), vol. 20, People's Medical Publishing House, Beijing: 1998, 184.

4. Sung YI, Koike K, Nikaido T, Ohmoto T, Sankawa U. Inhibitors of cyclic AMP phosphodiesterase in Picrasma quassioides Bennet, and inhibitory activities of related $\beta$-Carboline alkaloids. Chem Pharm Bull 1984; 32(51): 1872-1877.

5. Ohmoto T, Sung YI, Koike K, Nikaido T. Effect of alkaloids of simaroubaceous plants on the local blood flow rate. Shoyakugaku Zasshi 1985; 39(1): 28-34.

6. Chen J, Yan XH, Dong JH, Sang P, Fang X, Di YT, Zhang ZK, Hao XJ. Tobacco Mosaic Virus (TMV) Inhibitors from Picrasma quassioides Benn. $J$ of Agric Food Chem 2009; 57(15): 6590-6595.

7. Yin Y, Heo SI, Roh KS, Wang MH. Biological activities of fractions from methanolic extract of Picrasma quassioides. J of Plant Biol 2009; 52(3): 325-331.

8. Jiao WH, Gao H, Zhao F, Lin HW, Pan YM, Zhou GX, Yao $X S$. Antiinflammatory alkaloids from the stems of Picrasma quassioides BENNET. Chem Pharm Bull 2011; 59(3): 359-364.

9. Liu JF, Shao M, Zhai DW, Liu K, Wu LJ. Protective effect of 4-Methoxy-5-hydroxycanthin-6-one, a natural alkaloid, on dextran sulfate sodium-induced rat colitis. Planta Med 2009; 75(2): 142-145.

10. Yin $Y$, Lee SK, Wang MH. Isolation and biological activities of an alkaloid compound (3-methylcanthin5, 6-dione) from Picrasma quassiodes (D. Don) Benn. Nat Prod Sci 2011; 17(1): 5-9.

11. Yang WH, Xiao SX, Zheng JH. Authentication of Kumu injection. Lishizhen Med and Mater Med Res 2001; 12(4): 338.

12. Huang WD, Song $Y X, L v$ WQ. Determination of canthinones alkaloids in Kumu injection by HPLC. Chin J Hosp Pharm 2010; 30(5): 1066-1067.

13. Ohmoto $T$, Koike $K$. Studies on the constituents of Picrasma quassioides Bennet. III. Chem Pharm Bull 1984; 32(9): 3579-3583.

14. Ohmoto $T$, Koike K. Studies on the alkaloids from Picrasma quassioides Bennet. VI. Chem Pharm Bull 1985; 33(11): 4901-4905. 